\title{
Characteristics of Lightning Jumps Associated with a Tornadic Supercell on 2 September 2013
}

\author{
Masahide Nishihashi, Ken-ichiro Arai, Chusei Fujiwara, Wataru Mashiko, \\ Satoru Yoshida, Syugo Hayashi, and Kenichi Kusunoki \\ Meteorological Research Institute, Tsukuba, Japan
}

\begin{abstract}
Cloud-to-ground (CG) and total (both $\mathrm{CG}$ and intracloud) lightning trends were investigated in a tornado-producing (F2) supercell thunderstorm that occurred over the Kanto Plain in Japan on 2 September 2013. The spatiotemporal signatures of mesocyclone (MC) and storm development were also analyzed using Doppler radar data. The results revealed that rapid increases of lightning flash rates ("lightning jumps") occurred in CG and total flash rates $0-7$ and $0-14$ min before tornadogenesis, respectively, which are similar to those observed in the United States. However, the CG polarity change reported in previous studies was not observed, i.e., $96 \%$ of $C G$ flashes were negative. The vertical vorticity of the MC was larger in the mid-level $(4-6 \mathrm{~km})$ than the low level $(2 \mathrm{~km})$ at the beginning stage of the lightning jumps, which might have led to updraft enhancement above the freezing level appropriate for the rapid increases in lightning flash rates.

(Citation: Nishihashi, M., K. Arai, C. Fujiwara, W. Mashiko, S. Yoshida, S. Hayashi, and K. Kusunoki, 2015: Characteristics of lightning jumps associated with a tornadic supercell on 2 September 2013. SOLA, 11, 18-22, doi:10.2151/sola.2015-005.)
\end{abstract}

\section{Introduction}

Many studies have documented evidence that lightning activity is associated with severe weather such as wind gusts, tornadoes, and hail (e.g., Goodman et al. 1988; MacGorman et al. 1989; Williams et al. 1989; MacGorman and Nielsen 1991). Recent studies have shown that the lightning flash rate increases rapidly before the onset of severe weather events (e.g., Williams et al. 1999; Goodman et al. 2005; Steiger et al. 2007). These abrupt increases of the lightning flash rate over short periods of time have been termed "lightning jumps" by Williams et al. (1999). If such rapid increases could be detected adequately, then lightning data could be used as part of the severe weather warning decision-making process. Thus, algorithms to identify severe weather using the trends of flash rates have been developed (Schultz et al. 2009; Gatlin and Goodman 2010). Schultz et al. (2011) examined cloud-to-ground (CG) and total (both CG and intracloud) lightning trends for 711 thunderstorms and applied lightning jump algorithms. The results showed that while both lightning datasets demonstrated the presence of lightning jumps prior to the onset of severe weather, the use of total lightning trends was more effective than CG trends.

These approaches have been conducted in association with severe weather in the United States, but there have been only a few reports of CG trends in Japan. Kobayashi and Sugawara (2009) investigated a tornadic thunderstorm in Saroma, Hokkaido and found that the CG frequency peaked shortly before tornadogenesis. Kobayashi and Yamaji (2013) examined the CG trend during an F3-tornado-producing supercell in Tsukuba. While the peak CG frequency occurred 20 minutes before the tornado, the number of CGs decreased significantly during its lifetime. On average, discounting waterspouts, 25 tornadoes have occurred in Japan per year during 2007-2013 (http://www.data.jma.go.jp/obd/

Corresponding author: Masahide Nishihashi, Meteorological Research Institute, 1-1 Nagamine, Tsukuba, Ibaraki 305-0052, Japan. E-mail: nisihasi (a)gmail.com. (C)2015, the Meteorological Society of Japan. stats/data/bosai/tornado/stats/annually.html). Tornadoes related to supercells produce considerably more damage (Niino et al. 1993) than non-supercell tornadoes do. Therefore, the improvement of methods for monitoring and forecasting supercell tornadoes is important for disaster prevention.

A severe storm occurred over the Kanto Plain on 2 September 2013 and it produced an F2 tornado that persisted between 1400-1430 Japan Standard Time (JST; JST $=$ UTC +9 h). The tornado had a track that was $19-\mathrm{km}$ long and 300-m wide (Japan Meteorological Agency 2013) and it caused injury to 76 people and damaged 247 houses (http://www.data.jma.go.jp/obd/stats/ data/bosai/tornado/new/list_new.html) in Saitama, Koshigaya, Matsubushi, Noda, and Bando (Fig. 1b). The typical characteristics of a classic supercell such as a mesocyclone (MC), hook echo, and vault structure have been identified in the tornadic storm (Kato et al. 2014). Moreover, hail falls were recorded beneath the storm (Tokyo Broadcasting System Television 2013).

In this paper, we focus on the lightning jumps in both $\mathrm{CG}$ and total lightning before the supercell tornado and on the related spatiotemporal signatures of $\mathrm{MC}$ and storm development.

\section{Data and methodology}

We used lightning data observed by the Lightning Detection Network (LIDEN) system operated by the Japan Meteorological Agency (JMA) for aviation safety (JMA 2001). The LIDEN consists of 30 observation sites (Fig. 1a) and a central processor. It is a hybrid system of a time-of-arrival method in the low frequency (LF) band for return strokes (involved in CG flashes), and an interferometric technique in the very high frequency (VHF) band for VHF radiation sources associated with discharges within thunderclouds. The typical location accuracy estimated from the technical specifications was a few kilometers in the Kanto Plain (Suzuki et al. 2012). The average detection efficiency deduced from visual observations was $70 \%$ for CG lightning (Kasahara 2011) and $83 \%$ for total lightning (JMA 2001, personal communication). In this paper, we define the flash rates estimated from the LF and VHF systems as the CG lightning flash rate (CGFR) and total lightning flash rate (TFR), respectively, and rapid increases over durations of at least $2 \mathrm{~min}$ (average increasing rate: $\geq 1.5$ flashes $\mathrm{min}^{-2}$ in CGFR and $\geq 10$ flashes $\min ^{-2}$ in TFR) as lightning jumps. The CGFR is the number of CG flashes per minute within the analyzed area $(18 \times 18 \mathrm{~km})$ indicated by the blue rectangles in Figs. 2a, b, c, $\mathrm{d}$, because we analyze lightning activity associated with the strong updraft around the MC in the supercell. Unfortunately, most total lightning flashes detected by the VHF system were located near the baselines of the observation sites (Haneda-Oshima and Haneda-Fukushima; Figs. 1a, b), where two-dimensional images cannot be obtained clearly by triangulation. In addition, VHF waves are possibly affected by geography and their propagation distances are shorter than LF waves so that the triangulation method might degrade two-dimensional images. To avoid using mis-location data, the TFR is defined as the number of total lightning flashes per minute located in the direction of the supercell (the CGFR analyzed area) from Haneda (Fig. 1b). The Haneda site was the nearest observation site to the supercell. During the analyzed period, no thunderstorm other than the supercell was detected in the direction of the supercell from Haneda.

We also utilized radar reflectivity and Doppler velocity data observed by the Doppler Radar for Airport Weather (DRAW) 


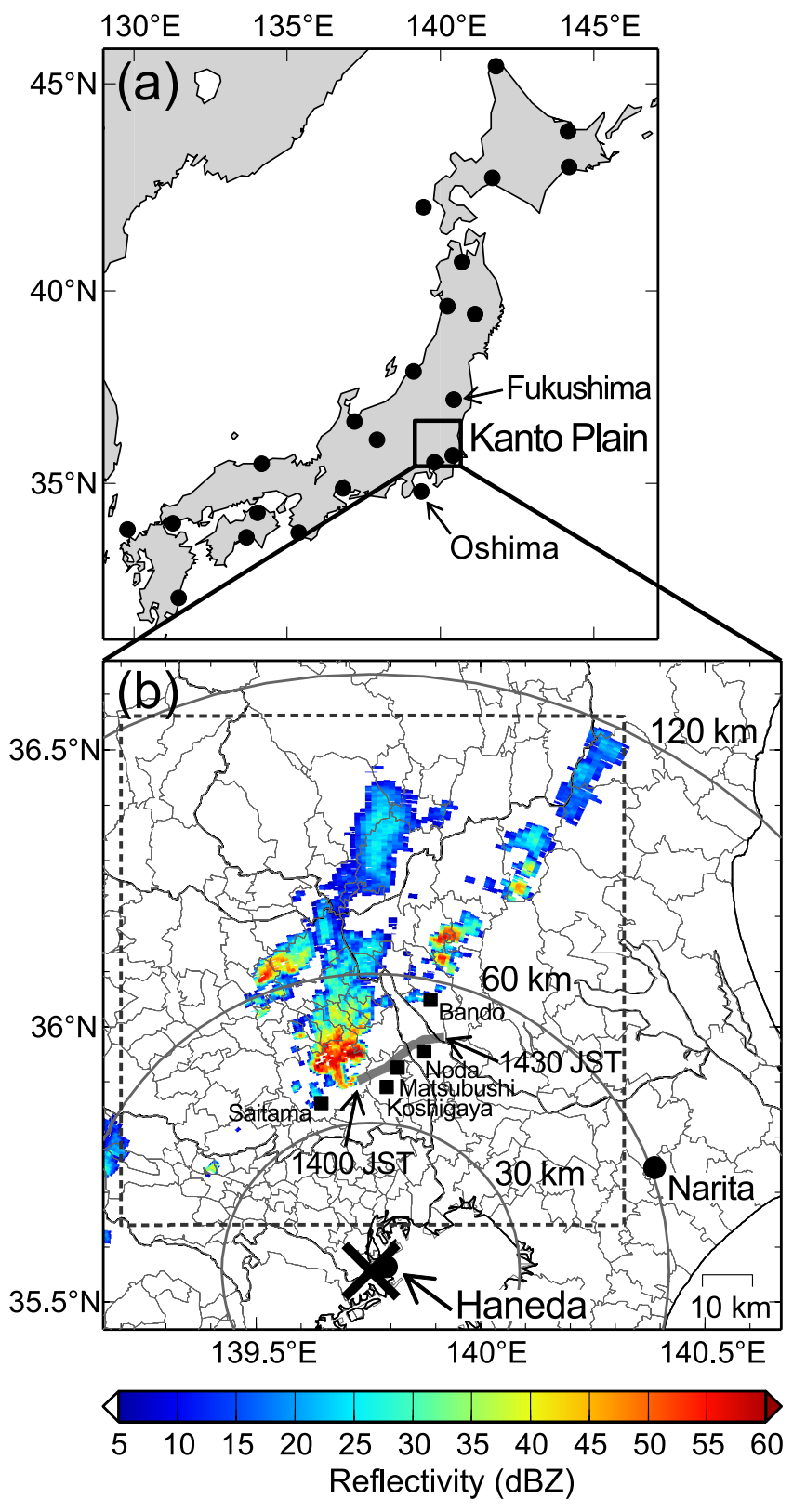

Fig. 1. Locations of the observation sites of the LIDEN (filled circles), DRAW at Haneda Airport (cross), the tornado track (gray thick line, lifetime: 1400-1430 JST), and the damaged municipalities (filled squares). (a) Location of the Kanto Plain, Japan. (b) Radar reflectivity observed with the DRAW (PPI scan, elevation: $3.4^{\circ}$ ) at 1401:09 JST. The square delineated by the dashed line in (b) indicates the study area for the CAPPI and TBB data.

at Haneda Airport (Fig. 1b) (Ishihara 1997). This is a 5.28-GHz C-band Doppler radar with maximum observational range of $120 \mathrm{~km}$, resolutions of $0.7^{\circ}$ in the azimuthal direction and $150 \mathrm{~m}$ in the radial direction, and an update interval of $5 \mathrm{~min} 50 \mathrm{sec}$ for a volume scan (16 elevations). Using the volume scan data, we obtained constant altitude plan position indicator (CAPPI) data with range of $100 \times 100 \times 20 \mathrm{~km}$ (Fig. 1b), horizontal resolution of $0.25 \mathrm{~km}$, and vertical resolution of $0.5 \mathrm{~km}$.

MCs were identified manually by finding the couplet of Doppler velocity maximum $\left(V_{\max }\right)$ and minimum $\left(V_{\min }\right)$ for each plan position indicator (PPI) scan. The Doppler velocities were dealiased automatically, but for quality control purposes around $\mathrm{MCs}$, we performed manual dealiasing. Assuming rigid-body rotation, the vertical vorticity $\zeta$ was computed as $\zeta=4 V_{t} / d$, where $V_{t}$ is the peak tangential velocity defined as $V_{t}=\left(V_{\max }-V_{\min }\right) / 2$ and $d$ is the core diameter retrieved from the distance between $V_{\max }$ and $V_{\min }$. We examined those MCs with $d>2 \mathrm{~km}$ in this paper.

The JMA has conducted a Rapid Scan Operation (RSO) with a 5-min interval on the Multi-functional Transport Satellite-1R (MTSAT-1R). The spatial resolution of RSO images for infrared (IR) channels is $4 \mathrm{~km}$ at the sub-satellite point (Okabe et al. 2011). The equivalent blackbody temperature (TBB) of IR1 (10.3$11.3 \mu \mathrm{m})$ was calculated from RSO data to evaluate the development of thunderclouds.

\section{Results}

Figure $1 \mathrm{~b}$ shows the radar reflectivity observed with the DRAW (PPI scan, elevation: $3.4^{\circ}$ ) at 1401:09 JST and the tornado track. The radar scan time in this paper indicates the termination time of each PPI scan. The F2 tornado occurred in the southern edge of the supercell (Kato et al. 2014) at 1400 JST and moved east-northeast with a horizontal speed of about $11 \mathrm{~m} \mathrm{~s}^{-1}$ for $30 \mathrm{~min}$. During this period, the horizontal distances between the DRAW and the tornado varied from $40-50 \mathrm{~km}$.

Figure 2 illustrates the spatial distribution of the TBB in the entire supercell, and radar reflectivity, Doppler velocity (PPI scan, elevation: $3.4^{\circ}$, height: $2.4-3.0 \mathrm{~km}$ ), and CG flashes in the southern part of the supercell. The supercell was extended significantly in the horizontal and vertical directions (Figs. 2a, b, c, d). The radar reflectivity, observed at 1401:09 JST, shows an apparent hook echo and a weak echo region that are typical characteristics of a supercell (Fig. 2f). The hook echo was apparent at 1349:28 JST and the reflectivity in the hook echo increased from 20 to 50 dBZ (1349:28-1401:09 JST) (Figs. 2e, f). Moreover, the large area of reflectivity $(>50 \mathrm{dBZ})$ on the northern side of the hook echo increased at 1401:09 JST (Fig. 2f) and in this area, a number of CG flashes were located.

Figures $3 \mathrm{a}, \mathrm{b}$ show the 1-min CGFR and TFR from 1300 to $1440 \mathrm{JST}$. Figure $3 \mathrm{e}$ shows the time-height evolution of the maximum radar reflectivity inside the analysis domain (Fig. 1b), illustrated from the CAPPI data. The 40-dBZ echo developed and exceeded the $-10^{\circ} \mathrm{C}$ level around 1325 JST (Fig. 3e). CG and total lightning flashes were detected from 1331 JST (Figs. 3a, b). The probability of lightning increases when the 40-dBZ echo exceeds the $-10^{\circ} \mathrm{C}$ level (e.g., Buechler and Goodman 1990). The CGFR increased rapidly from 5 to 20 flashes $\mathrm{min}^{-1}$ (13531400 JST), i.e., a lightning jump in the CGFR occurred 0-7 min before tornadogenesis at 1400 JST. After tornadogenesis, the CGFR maintained high values of 17 flashes $\mathrm{min}^{-1}$ on average and peaked at 1411 and 1412 JST (23 flashes $\mathrm{min}^{-1}$ ). While the tornado persisted until 1430 JST, the CGFR decreased gradually and reached 2 flashes $\min ^{-1}$ at the time of tornado dissipation. Positive CG (+CG) flashes were detected from 1353 to 1419 JST (Fig. 3a), but the +CGFR showed no abrupt change (0-3 flashes $\left.\min ^{-1}\right)$. Before tornadogenesis, the maximum +CGFR was 2 flashes min $^{-1}$ at 1359 JST. Thus, most CG flashes (96\%) were negative CG (-CG) flashes. Meanwhile, 0-14 min before tornadogenesis, three lightning jumps in the TFR occurred during the following periods: 1) from 15 to 50 flashes $\min ^{-1}$ (1346-1348 JST), 2) from 33 to 78 flashes $\mathrm{min}^{-1}$ (1353-1356 JST), and 3) from 45 to 90 flashes $\mathrm{min}^{-1}$ (1358-1400 JST). After the maximum TFR of 93 flashes $\min ^{-1}$ at 1403 JST, the TFR decreased significantly from 71 to 11 flashes $\min ^{-1}(1409-1413$ JST).

The time-height evolution of the large reflectivity $(>50 \mathrm{dBZ})$ area is shown in Fig. 3c. The size of the $>50-\mathrm{dBZ}$ area began to increase at the height of $5-6 \mathrm{~km}\left(0\right.$ to $-10^{\circ} \mathrm{C}$ region $)$, exceeding $4 \mathrm{~km}^{2}$ around $1340 \mathrm{JST}$. The time of this extension is consistent with the increase in the CGFR and TFR. While the CGFR and TFR increased rapidly from 1345 to 1400 JST, the size of the $>50-\mathrm{dBZ}$ area also increased and reached a peak of $20 \mathrm{~km}^{2}$ at around the height of $4-5 \mathrm{~km}$ (approximately the $0^{\circ} \mathrm{C}$ level). At around $1350 \mathrm{JST}$, the height of the $40-\mathrm{dBZ}$ contour increased rapidly from 10 to $14 \mathrm{~km}$, and the 20-dBZ echo-top height developed to about $17 \mathrm{~km}$ (Fig. 3e). The minimum TBB inside the analysis 


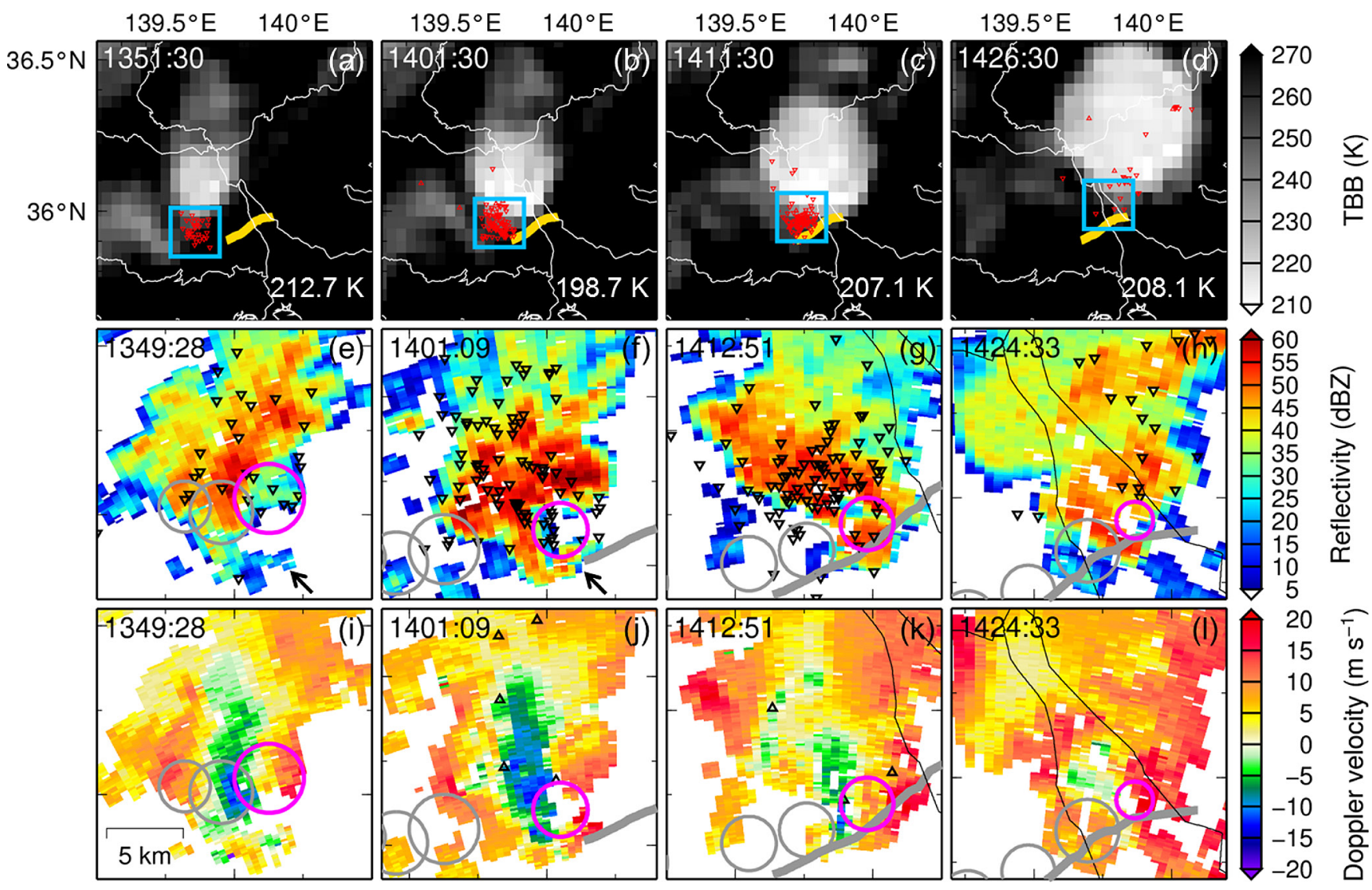

Fig. 2. Locations of + CG flashes [triangles; (a)-(d), (i)-(1)] and -CG flashes [inverted triangles; (a)-(d), (e)-(h)] observed with the LIDEN and the tornado track (thick line). (a)-(d) Spatial distribution of the TBB obtained from the infrared observation of the MTSAT-1R and (e)-(h) radar reflectivity and (i)(1) Doppler velocity observed with the DRAW (PPI scan, elevation: $3.4^{\circ}$, height: $2.4-3.0 \mathrm{~km}$ ). The time shown in each panel represents the scan time. The temperature shown in (a)-(d) indicates the minimum TBB in the plotted area. The CG flashes are plotted from the time 5 min prior to the corresponding scan time to the scan time. The rectangles delineated by the blue line in (a)-(d) indicate the plot area for (e)-(1). The circles denote the location and core diameter of the identified MC (magenta circle: MC observed by the same scan, gray circle: history of the MC). Arrows in (e) and (f) indicate the location of the hook echo.

domain (Fig. 1b) reached its lowest value of 198.7 K at 1401:30 JST (Fig. 3e). Following the descent of the $>50-\mathrm{dBZ}$ area toward the ground by $1410 \mathrm{JST}$, the size of the $>50-\mathrm{dBZ}$ area became reduced in the mid-levels $\left(2-4 \mathrm{~km}^{2}\right.$ at $4-6 \mathrm{~km}$ height). The height of the 40-dBZ contour also descended rapidly from 15 to $10 \mathrm{~km}$.

We identified MCs from 1337 to 1436 JST. The locations of the MCs identified in each PPI scan data (elevation: $3.4^{\circ}$, height: $2.4-3.0 \mathrm{~km})$ at 1349:28, 1401:09, 1412:51, and 1424:33 JST are overlaid on the radar reflectivity and Doppler velocity images (Figs. 2e, f, g, h, i, j, k, l). In particular, an MC with a large velocity difference couplet was identified around the hook echo at 1401:09 JST, immediately after tornadogenesis. The core diameter, peak tangential velocity, and vertical vorticity of the MC were $3.6 \mathrm{~km}, 22.2 \mathrm{~m} \mathrm{~s}^{-1}$, and $0.025 \mathrm{~s}^{-1}$, respectively. The timeheight variations of the $\mathrm{MC}$ core diameter and vorticity, which were identified in each PPI scan data, are illustrated in Figs. 3d, e, respectively. The vorticity of the mid-level MC at the height of 4-6 km was large (maximum: $0.027 \mathrm{~s}^{-1}$ ) compared with the vorticity of the low-level MC at 2-km height $\left(0.012 \mathrm{~s}^{-1}\right)$ at $1350 \mathrm{JST}$ (10 min before tornadogenesis). The core diameter of the MC was approximately $3.5 \mathrm{~km}$ in the mid-level, which was $1 \mathrm{~km}$ smaller than in the low level. Meanwhile, at 1400 JST, i.e., the time of tornadogenesis, vorticity was larger in the low level than in the mid-level (low level: $0.027 \mathrm{~s}^{-1}$, mid-level: $0.014-0.021 \mathrm{~s}^{-1}$ ). The core diameter was $4-5 \mathrm{~km}$ in the mid-level, but just $3 \mathrm{~km}$ in the low level at the same time. Until the tornado dissipated, the large vorticity in the low level was maintained. Concurrently, the following phenomena were observed in the MC: the shrinkage of the core diameter $(2-3 \mathrm{~km})$ in the low level, upward development of the vortex signatures $(>10 \mathrm{~km})$, and increase of the core diameter $(5-10 \mathrm{~km})$ in the mid- and high levels.

\section{Discussion}

\subsection{Lightning jumps compared with previous studies}

The lightning jumps in the CGFR and TFR were observed 0-7 and $0-14$ min before tornadogenesis, respectively (Figs. 3a, b). The rate of increase in the TFR (15-23 flashes $\left.\mathrm{min}^{-2}\right)$ was greater than in the CGFR (2.1 flashes $\mathrm{min}^{-2}$ ). Williams et al. (1999) reported lightning jumps in TFRs $\left(20\right.$ to $>100$ flashes $\mathrm{min}^{-2}$ ) 115 min before the onset of severe weather. Gatlin and Goodman (2010) reported that the increasing rate of TFR ( 6.8 flashes $\mathrm{min}^{-2}$ ) was much greater than CGFR $\left(0.2\right.$ flashes $\left.\operatorname{~min}^{-2}\right)$ before large hail events. Hence, the present results are consistent with previous studies and indicate that lightning jumps occurred just before tornadogenesis.

The values of CGFR $\left(>15\right.$ flashes $\left.\min ^{-1}\right)$ and TFR $(>70$ flashes $\mathrm{min}^{-1}$ ) just before tornadogenesis were extremely high and comparable with those observed in severe storms in the United States. Williams (2001) reported that CGFRs in severe storms in the United States exceed 10 flashes $\mathrm{min}^{-1}$, while CGFRs in non-severe storms rarely exceed 1 flash $\mathrm{min}^{-1}$. TFRs observed in non-severe storms are typically about 1-10 flashes $\min ^{-1}$ (e.g., Williams et al. 1999), but those observed in severe storms are $>60$ flashes $\mathrm{min}^{-1}$ (Williams et al. 1999), of the order of 100 flashes $\min ^{-1}$ (Williams 2001), or of the order of 10 flashes $\min ^{-1}$ or greater (Tessendorf 2009). The values of CGFR and TFR in the 


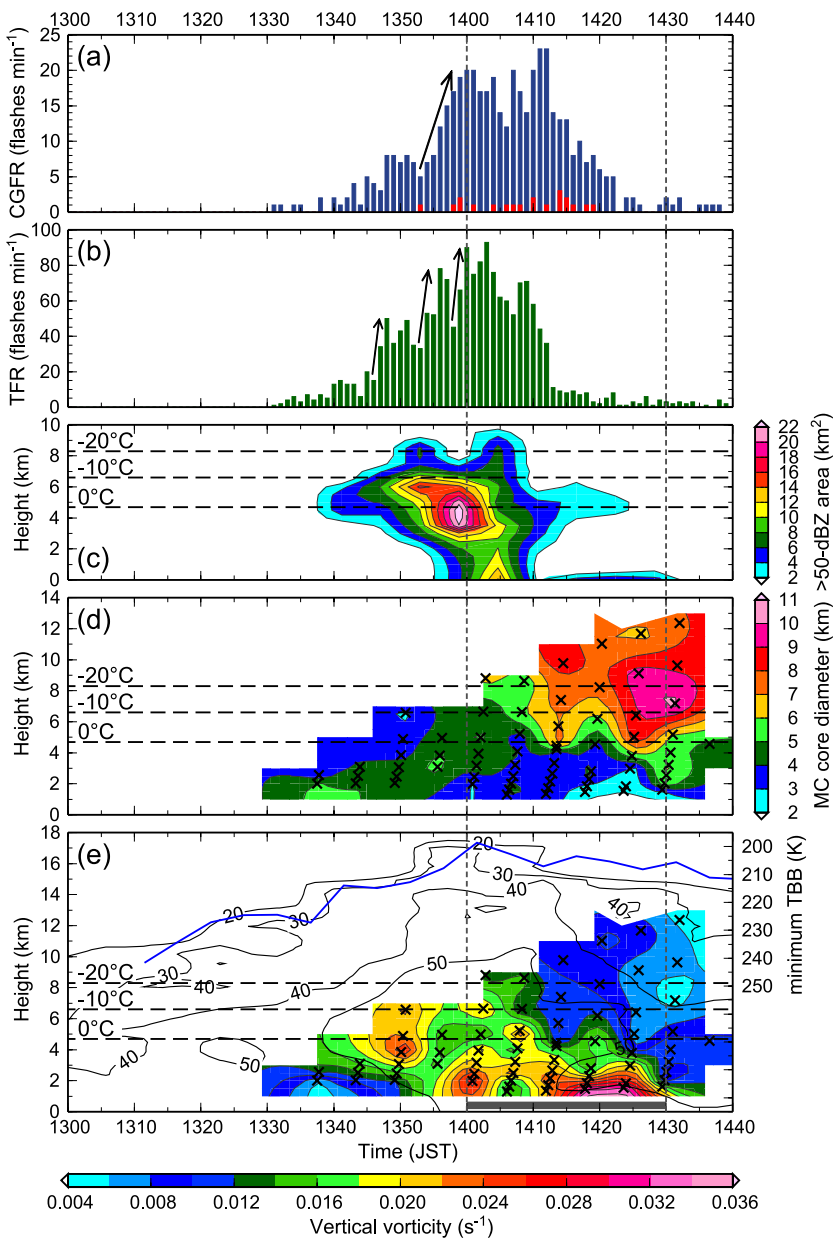

Fig. 3. (a) Stacked bar chart of the 1-min +CGFR (red bars) and -CGFR (blue bars) and (b) bar chart of the 1-min TFR. Time-height plots of (c) the $>50-\mathrm{dBZ}$ area, (d) core diameter and (e) vertical vorticity of the MC (shading), which were identified in each PPI scan data, and maximum radar reflectivity inside the analysis domain shown in Fig. 1b (contours with values). Blue line in (e) indicates the time history of the minimum TBB inside the study area (Fig. 1b), which was obtained from the infrared observation of the MTSAT-1R. Cross symbols show the beam heights of each radar scan. The lifetime of the tornado is drawn as the gray horizontal bar and vertical dashed lines. Horizontal dashed lines denote the temperature level $\left(0,-10,-20^{\circ} \mathrm{C}\right)$ retrieved from Mesoscale Analysis (MANAL) data released by the JMA. Arrows in (a) and (b) indicate the lightning jumps in the CGFR (1353-1400 JST) and TFR (1346-1348, 1353-1356, 1358-1400 JST) prior to tornadogenesis.

present study are similar to those reported in previous studies, while the variability of those in severe storms is apparent. Wiens et al. (2005) and Tessendorf (2009) suggested that it is better to focus on the general order of magnitude and trend of the flash rate because the quantitative flash rate depends on the specifications of the observational system and the mapping algorithms.

Goodman et al. (2005) documented that CGFRs increased 15-20 min before a supercell tornado in Tennessee, but that the CGFRs showed a significant lull 5-10 min before tornadogenesis. Such decreases in CGFRs have been observed before tornadogenesis in the United States (e.g., Kane 1991; Steiger et al. 2007) and Japan (Kobayashi and Yamaji 2013); however, the trend of the CGFR shown in Fig. 3a does not exhibit a similar reduction. Characteristic trends observed before and during tornadoes in supercells, such as the increase of +CGFR (e.g., Carey et al. 2003; Kobayashi and Yamaji 2013) and the polarity reversal of dominant CG flashes from positive to negative (e.g., Perez et al. 1997), were not observed in the present study.

\subsection{Mesocyclone (MC) and storm development}

At about the same time (1350 JST) as the first rapid increase of the TFR (1346-1348 JST), the vorticity in the mid-level MC (height of 4-6 km) was greater than in the low-level MC $(2-\mathrm{km}$ height) (Fig. 3e). Concurrently, the heights of the 40-dBZ and $20-\mathrm{dBZ}$ contours rose rapidly, suggesting that an intense updraft had been created above the mid-level. Rotunno and Klemp (1982) indicated that strong vorticity in the mid-level could produce an upward perturbation pressure gradient that would cause updraft enhancement during the early stages of an MC.

The $>50-\mathrm{dBZ}$ area also spread between the 0 and $-10^{\circ} \mathrm{C}$ levels (Fig. 3c). These large volumes of moderate-to-large reflectivities above the freezing level suggest that frozen precipitation (particularly graupel) was distributed (Emersic et al. 2011). TFRs are well correlated with the graupel echo volume (Wiens et al. $2005)$ and with updraft volume $\left(>5 \mathrm{~m} \mathrm{~s}^{-1}\right)$ above the $>-5^{\circ} \mathrm{C}$ level (Deierling and Petersen 2008). Hence, the present results imply that both the volume and the magnitude of the updraft were enhanced effectively by vorticity growth in the mid-level MC, and that a large amount of graupel was produced above the freezing level. It is suggested that the lightning jumps occurred because of a non-inductive charging process (NIC; Takahashi 1978), linked to rebounding collisions between graupel and ice crystals in the mixed-phase region.

The mid-level vorticity decreased at 1400 JST, but the lowlevel vorticity increased (Fig. 3e), indicating the descent of the MC core. From 1415 to 1430 JST, the low-level vorticity increased significantly. This result and the tornado lifetime $(\sim 1430$ JST) suggest that the strong updraft near the ground had been held by the low-level MC. However, the flash rates decreased substantially and both the height of the $40-\mathrm{dBZ}$ contour and size of the $>50-\mathrm{dBZ}$ area were also reduced. Thus, the decrease of the flash rates was probably caused by weakening of the NIC above the freezing level.

\section{Summary}

This study investigated lightning trends of the tornadic supercell over the Kanto Plain in Japan on 2 September 2013. The results indicate that the lightning jumps in not only CGFR but also TFR occurred just before tornadogenesis, as has been observed in the United States. However, the CG polarity change reported in previous studies was not observed in this case (i.e., $96 \%$ of CG flashes were negative). One possible reason for the lightning jumps was the updraft enhancement above the freezing level caused by the larger vorticity of the MC in the mid-level than in the low level.

\section{Acknowledgements}

LIDEN and DRAW data were provided by the Observation Department of JMA. The authors wish to thank Mr. Eiichi Sato for preparing the DRAW data and Dr. Tomoyuki Suzuki for his helpful discussions. Doppler radar data analyses were performed using the Doppler radar analysis tool "Draft". We wish to thank the reviewers for their useful comments.

\section{References}

Buechler, D. E., and S. J. Goodman, 1990: Echo size and asymmetry: Impact on NEXRAD storm identification. J. Appl. Meteor., 29, 962-969.

Carey, L. D., W. A. Petersen, and S. A. Rutledge, 2003: Evolution of cloud-to-ground lightning and storm structure in the Spencer, South Dakota, tornadic supercell of 30 May 1998. Mon. Wea. Rev., 131, 1811-1831.

Deierling, W., and W. A. Petersen, 2008: Total lightning activity as an indicator of updraft characteristics. J. Geophys. Res., 113, D16210. 
Emersic, C., P. L. Heinselman, D. R. MacGorman, and E. C. Bruning, 2011: Lightning activity in a hail-producing storm observed with phased-array radar. Mon. Wea. Rev., 139, $1809-1825$

Gatlin, P. N., and S. J. Goodman, 2010: A total lightning trending algorithm to identify severe thunderstorms. J. Atmos. Oceanic Technol., 27, 3-22.

Goodman, S. J., D. E. Buechler, P. D. Wright, and W. D. Rust, 1988: Lightning and precipitation history of a microburstproducing storm. Geophys. Res. Lett., 15, 1185-1188.

Goodman, S. J., R. Blakeslee, H. Christian, W. Koshak, J. Bailey, J. Hall, E. McCaul, D. Buechler, C. Darden, J. Burks, T. Bradshaw, and P. Gatlin, 2005: The North Alabama lightning mapping array: Recent severe storm observations and future prospects. Atmos. Res., 76, 423-437.

Ishihara, M., 1997: Doppler radar for airport weather (DRAW) operation started (Explanation part) (in Japanese). Radar Kansoku Gijyutsu Shiryou, 46, 1-26.

Japan Meteorological Agency, 2001: Introduction of LIDEN (in Japanese). Kisho, 45, 17426-17429.

Japan Meteorological Agency, 2013: Wind gust occurred in Saitama, Koshigaya, Matsubushi, Noda, and Bando on 2 September 2013 (in Japanese). Natural Disaster Survey Report, Japan Meteorological Agency, 29 pp. [Available online at http://www.data.jma.go.jp/obd/stats/data/bosai/tornado/new/ 2013090201/20130902_saitama.pdf]

Kane, R. J., 1991: Correlating lightning to severe local storms in the northeastern United States. Wea. Forecasting, 6, 3-12.

Kasahara, S., 2011: Lightning analysis and forecasting technology in lightning nowcast and the usage (in Japanese). Wea. Service Bull., 78, 95-140. [Available online at http://www.jma. go.jp/jma/kishou/books/sokkou/78/vol78p095.pdf]

Kato, T., Y. Sumida, and Y. Tanaka, 2014: Occurrence factor of the Koshigaya-Noda tornado on 2 September 2013 (in Japanese). Preprints, 2014 Spring Meeting of the Meteorological Society of Japan, Yokohama, Meteorological Society of Japan, B456.

Kobayashi, F., and Y. Sugawara, 2009: Cloud-to-ground lightning characteristics of the tornadic storm over Hokkaido on November 7, 2006. J. Atmos. Electr., 29, 1-12.

Kobayashi, F., and M. Yamaji, 2013: Cloud-to-ground lightning features of tornadic storms occurred in Kanto, Japan, on May 6, 2012. J. Disaster Res., 8, 1071-1077.

MacGorman, D. R., and K. E. Nielsen, 1991: Cloud-to-ground lightning in a tornadic storm on 8 May 1986. Mon. Wea. Rev., 119, 1557-1574.

MacGorman, D. R., D. W. Burgess, V. Mazur, W. D. Rust, W. L. Taylor, and B. C. Johnson, 1989: Lightning rates relative to tornadic storm evolution on 22 May 1981. J. Atmos. Sci., 46, 221-251.

Niino, H., O. Suzuki, H. Nirasawa, T. Fujitani, H. Ohno, I. Takayabu, N. Kinoshita, and Y. Ogura, 1993: Tornadoes in Chiba prefecture on 11 December 1990. Mon. Wea. Rev., 121, 3001-3018.

Okabe, I., T. Imai, and Y. Izumikawa, 2011: Detection of rapidly developing cumulus areas through MTSAT rapid scan operation observations. Meteor. Satellite Center Tech. Note, 55, 69-91. [Available online at http://www.data.jma.go.jp/ mscweb/technotes/msctechrep55-2.pdf]

Perez, A. H., L. J. Wicker, and R. E. Orville, 1997: Characteristics of cloud-to-ground lightning associated with violent tornadoes. Wea. Forecasting, 12, 428-437.

Rotunno, R., and J. B. Klemp, 1982: The influence of the shearinduced pressure gradient on thunderstorm motion. Mon. Wea. Rev., 110, 136-151.

Schultz, C. J., W. A. Petersen, and L. D. Carey, 2009: Preliminary development and evaluation of lightning jump algorithms for the real-time detection of severe weather. J. Appl. Meteor. Climatol., 48, 2543-2563.

Schultz, C. J., W. A. Petersen, and L. D. Carey, 2011: Lightning and severe weather: A comparison between total and cloudto-ground lightning trends. Wea. Forecasting, 26, 744-755.

Steiger, S. M., R. E. Orville, and L. D. Carey, 2007: Total lightning signatures of thunderstorm intensity over North Texas. Part I: Supercells. Mon. Wea. Rev., 135, 3281-3302.

Suzuki, T., M. Hayakawa, Y. Hobara, and K. Kusunoki, 2012: First detection of summer blue jets and starters over Northern Kanto area of Japan: Lightning activity. J. Geophys. Res., 117, A07307.

Takahashi, T., 1978: Riming electrification as a charge generation mechanism in thunderstorms. J. Atmos. Sci., 35, 1536-1548.

Tessendorf, S. A., 2009: Characteristics of lightning in supercells. Lightning: Principles, Instruments and Applications, H. D. Betz et al., Eds., Springer, 83-114.

Tokyo Broadcasting System Television, 2013: NEWS23 [airdate: 2 September 2013].

Wiens, K. C., S. A. Rutledge, and S. A. Tessendorf, 2005: The 29 June 2000 supercell observed during STEPS. Part II: Lightning and charge structure. J. Atmos. Sci., 62, 4151-4177.

Williams, E. R., 2001: The electrification of severe storms. Severe Convective Storms, Meteor. Monogr., No. 50, Amer. Meteor. Soc., 527-561.

Williams, E. R., M. E. Weber, and R. E. Orville, 1989: The relationship between lightning type and convective state of thunderclouds. J. Geophys. Res., 94, 13213-13220.

Williams, E., B. Boldi, A. Matlin, M. Weber, S. Hodanish, D. Sharp, S. Goodman, R. Raghavan, and D. Buechler, 1999: The behavior of total lightning activity in severe Florida thunderstorms. Atmos. Res., 51, 245-265.

Manuscript received 4 October 2014, accepted 27 December 2014 SOLA: https://www.jstage.jst.go.jp/browse/solal 